\title{
Unidirectional porous beta-tricalcium phosphate and hydroxyapatite artificial bone: a review of experimental evaluations and clinical applications
}

\author{
Toru Funayama $^{1} \mathbb{D} \cdot$ Hiroshi Noguchi $^{1} \cdot$ Hiroshi Kumagai $\cdot$ Kosuke Sato $^{1} \cdot$ Tomokazu Yoshioka $^{1} \cdot$ Masashi Yamazaki $^{1}$
}

Received: 8 February 2021 / Accepted: 12 April 2021 / Published online: 23 April 2021

(c) The Author(s) 2021

\begin{abstract}
In Japan, where allograft bone transplantation is not widespread, prospects for artificial bones are very high. Therefore, artificial bones with various compositions, porous structures, and porosities have been developed and employed for clinical use. Both Affinos ${ }^{\circledR}$ and Regenos ${ }^{\circledR}$ (made of beta-tricalcium phosphate and hydroxyapatite, respectively) are artificial bones with a unique unidirectional porous structure, in which pores with a diameter suitable for tissue penetration $(25-300 \mu \mathrm{m})$ are aligned in one direction. The unidirectional porous structure allows rapid penetration of blood deep into the materials by a capillary effect. In animal experiments, Affinos ${ }^{\circledR}$ showed well-balanced resorption and was replaced with the host's own bone from an early stage after implantation and new bone formation and remodeling were observed in the cortical bone and medullary cavity. When implanted for clinical situation, resorption from an early stage and good replacement with the patient's own bone were also observed. Regenos ${ }^{\circledR}$ has an internal osteon-like material and a vascular-like structure that is maintained within the pores even after long-term implantation, as noted in an animal experiment. When implanted for clinical situation, good osteoconductivity was observed from an early stage of implantation. In addition, the material was observed to be slowly absorbed over time in some cases. We have discussed the beneficial effects of combining teriparatide and platelet-rich plasma impregnation and the potential prospects of these artificial bones.
\end{abstract}

Keywords Artificial bone $\cdot$ Unidirectional porous structure $\cdot$ Bone grafting $\cdot$ Hydroxyapatite $\cdot$ Beta-tricalcium phosphate

\section{Introduction}

Toru Funayama

funatoru3@md.tsukuba.ac.jp

$\triangle$ Hiroshi Noguchi

noguhiro0164@gmail.com

Hiroshi Kumagai

hiroshikumagai20@gmail.com

Kosuke Sato

junkrown@gmail.com

Tomokazu Yoshioka

tymd99@tsukuba-seikei.jp

Masashi Yamazaki

masashiy@md.tsukuba.ac.jp

1 Department of Orthopaedic Surgery, Faculty of Medicine, University of Tsukuba, 1-1-1 Tennodai, Tsukuba, Ibaraki 3058575, Japan
Bone grafting is frequently performed in orthopedic surgery [1]. The types of grafted bones vary depending on the country, and in Japan, current trends indicate that autologous bones account for $56.4 \%$ of grafts, followed by artificial bones at $40 \%$, and allogenic bones at 3.6\% [2]; the latter are used in limited cases, such as filling massive bony defects in hip replacements [3]. Although autologous bones are ideal filling materials, there is a risk of complications associated with harvesting [4]. Since the number of patients with osteoporosis is increasing due to the rapidly aging population in recent years, the quantity and quality of autogenous bones that can be harvested are limited. Thus, in Japan, the prospective applications for artificial bones in orthopedic surgery are high. Artificial bones with various compositions, porous structures, and porosities have been developed and employed for clinical use (Table 1). Artificial bones 


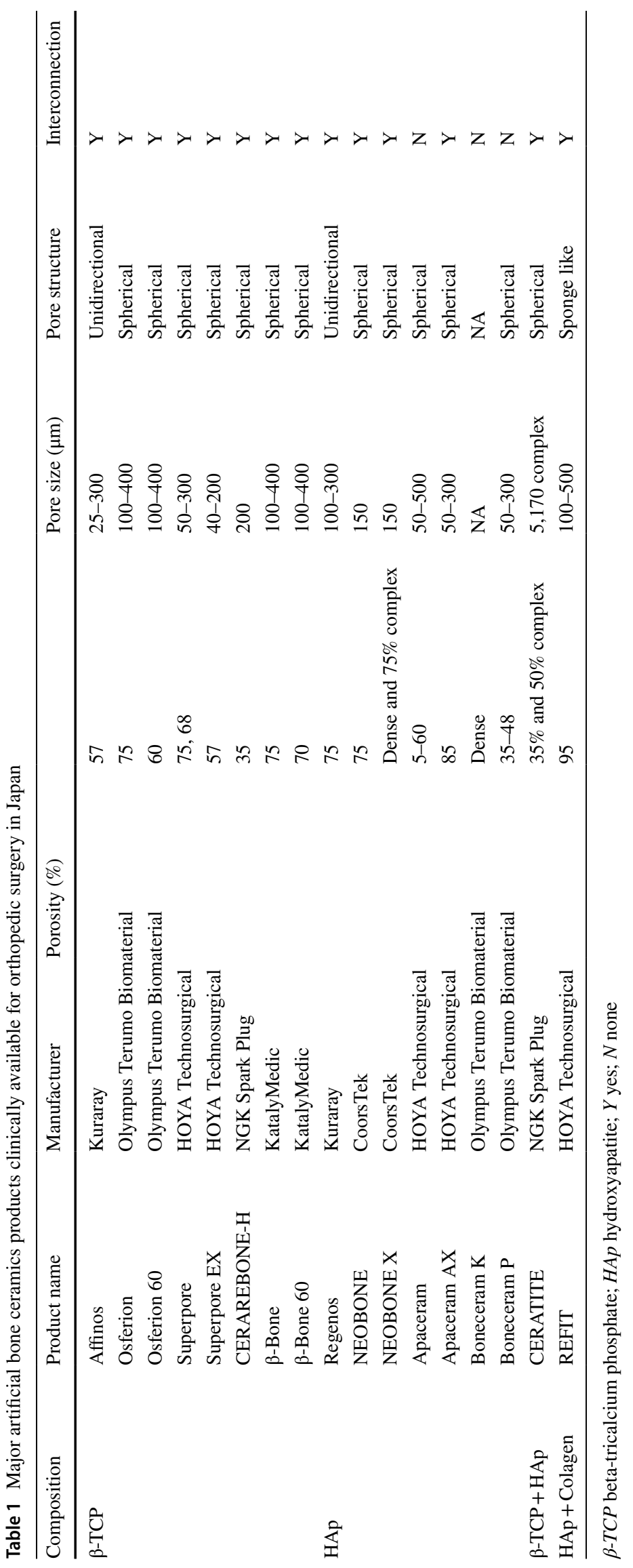


currently used in orthopedic surgery in Japan are mainly composed of beta-tricalcium phosphate ( $\beta$-TCP), a resorbable bone regeneration material, and hydroxyapatite (HAp), which is not usually replaced by bone.

In collaboration with Kuraray Co., Ltd (Tokyo, Japan), we developed Affinos ${ }^{\circledR}$ and Regenos ${ }^{\circledR}$, artificial bones made of $\beta$-TCP and HAp, respectively, that present a unique unidirectional porous structure (Figs. 1, 2). The pores, 25-300 $\mu \mathrm{m}$ in diameter, are lined up in one direction. Artificial bones with a unidirectional porous structure are manufactured by cooling the raw materials with ice in a slurry state, which leads to the formation of ice pillars that are lined up in a vertical direction, like frost columns. When freeze-dried, sublimation of these ice columns produces pores [5]. The greatest feature is that the unidirectional porous structure allows blood to rapidly reach deep inside the material by a capillary effect $[6,7]$ (Supplementary file1; Affinos ${ }^{\circledR}$, and Supplementary file2; Regenos ${ }^{\circledR}$ ). Affinos ${ }^{\circledR}$ has a porosity of $57 \%$, and its micropores are believed to promote bone formation [7]. Initial compression strengths of 8 and $1.5 \mathrm{MPa}$ are applied in the directions parallel and perpendicular to the pores, respectively [7]. On the other hand, the porosity of Regenos ${ }^{\circledR}$ is $75 \%$, and initial compression strengths of 14 and 1.0 MPa are applied in directions parallel and perpendicular to the pores, respectively [5].

We herein aimed to comprehensively review the data obtained from animal experiments and the findings in clinical cases, regarding artificial bones with a unidirectional porous structure.

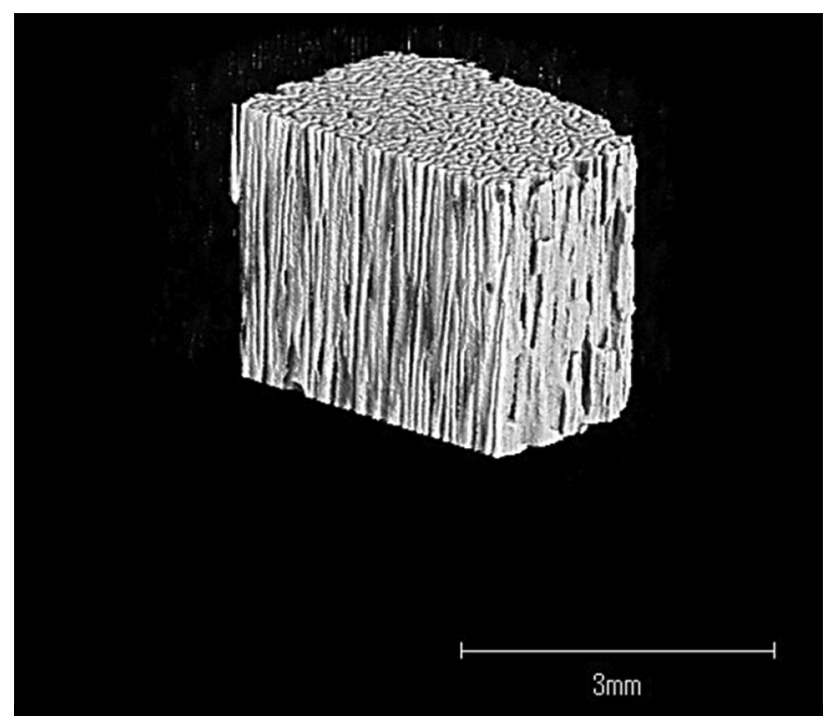

Fig. 1 Three-dimensional micro computed tomography image of Affinos ${ }^{\circledR}$, unidirectional porous $\beta$-TCP. The pores, $25-300 \mu \mathrm{m}$ in diameter, are lined up in one direction. The porosity is $57 \%$, and its initial compression strengths of 8 and 1.5 MPa are applied in the directions parallel and perpendicular to the pores, respectively

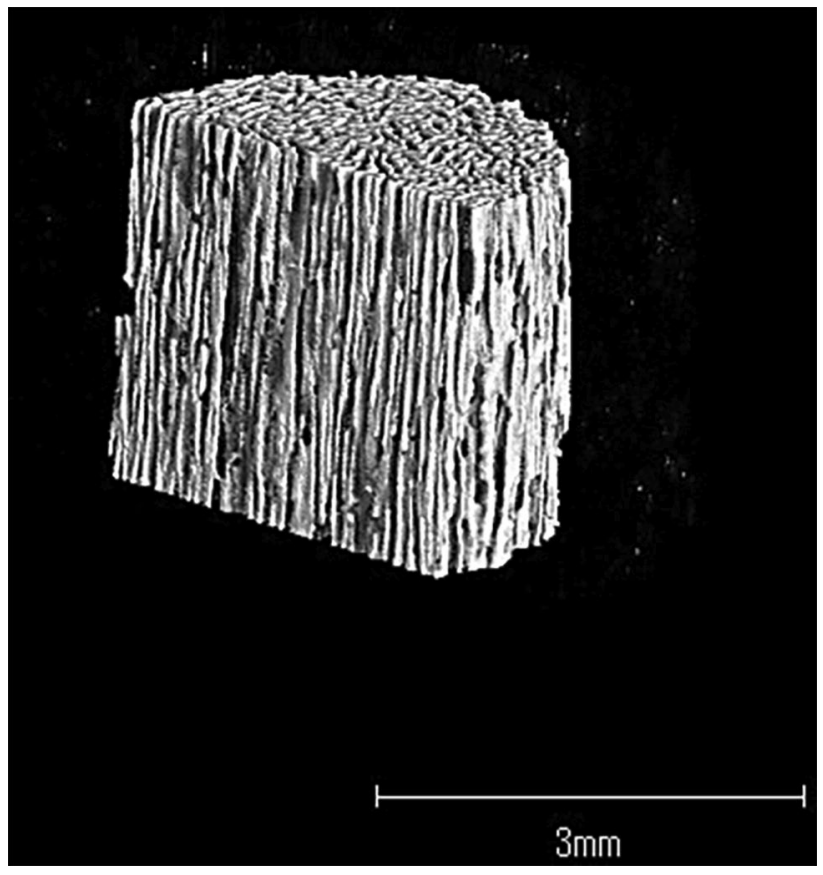

Fig. 2 Three-dimensional micro computed tomography image of Regenos ${ }^{\circledR}$, unidirectional porous HAp. The pores, $100-300 \mu \mathrm{m}$ in diameter, are lined up in one direction. The porosity is $75 \%$, and its initial compression strengths of 14 and $1.0 \mathrm{MPa}$ are applied in directions parallel and perpendicular to the pores, respectively

\section{Animal experiments during the development of Affinos ${ }^{\circledR}$, unidirectional porous $\beta$-TCP}

From an early stage of development, well-balanced resorption and replacement by the host bone were seen after implantation. This was observed after experimental grafting in the distal femur in a rabbit [8]. In another experiment in which bone grafting for tibial fenestration was performed in rabbits, the material was implanted in touch with both the cortical bone and the medullary cavity. New bone formation was observed throughout the interior of the material at 6 and 12 weeks after implantation. Replacement with host bone was evident in the cortical bone area, while material resorption and remodeling progressed in the medullary cavity [7]. In the same experimental model, histological assessment of the material after injecting dye into the blood vessels 6 weeks after implantation detected the presence of dye along with new bone formation within the material, confirming angiogenesis and the presence of blood flow [9]. Additionally, in an experiment conducted in beagle dogs where grafting was performed in a femoral bony defect, the entire 10-mm-long material was filled with new bone matching the porous direction at 3 months [10]. We examined the optimal mixing ratio of autogenous bone and Affinos ${ }^{\circledR}$ granules in an experimental beagle dog posterolateral lumbar spinal fusion 
model. It was determined that it is desirable to mix $50 \%$ or more of the autogenous bone when using Affinos ${ }^{\circledR}$ for grafting near or outside the bone [11]. In a study from a different facility, it was reported that Affinos ${ }^{\circledR}$ promotes angiogenesis than $\beta$-TCP bone with a spherical interconnected porous structure in a vascularized pedicle rat model [12].

\section{Clinical applications of Affinos ${ }^{\circledR}$, unidirectional porous $\beta$-TCP}

We have clinically used Affinos ${ }^{\circledR}$ in various orthopedic surgeries and reported those cases. We herein reviewed the published clinical reports in each orthopedic field.

\section{Trauma surgery}

When blocks and granules were used for calcaneal fractures, the artificial bones were resorbed in 3 months and nearly replaced with the patient's own bone in 6 months [13]. When blocks and granules weighing $25 \mathrm{~g}$, were used for an extensive bony defect during plate fixation in a supracondylar femoral fracture, absorption from the edge of the artificial bone mass was established after 6 months. Observations at 12 and 24 months confirmed that replacement of the material with the patient's own bone had progressed over time [10]. Although no absorption was seen at 3 months when blocks and granules were used for a large bony defect during plate fixation for pelvic fracture, they were completely replaced with the patient's own bone at 18 months [14]. Another institution also reported favorable outcomes with the use of Affinos ${ }^{\circledR}$ for bony defects during plate fixation in distal radius fractures [15].

\section{Osteotomy of the extremities}

When blocks and granules were used in the opening wedge during lateral column lengthening for pes planovalgus, resorption was evidenced at 3 months and complete replacement by the patient's own bone was confirmed at 12 months [10]. When Affinos ${ }^{\circledR}$ blocks and $\beta$-TCP with a spherical interconnected porous structure were implanted side by side in the osteotomy site in high tibial osteotomy for knee osteoarthritis, absorption and replacement by the patient's own bone occurred earlier in Affinos ${ }^{\circledR}$ blocks than in $\beta$-TCP with a spherical interconnected porous structure $[16,17]$.

\section{Spine surgery}

During pedicle screw fixation for fresh vertebral body fractures in older patients, granules were implanted in the bony defect as a vertebroplasty. In cases where loosening of the pedicle screw did not occur, resorption and replacement by the patient's own bone were observed as early as 3 months after surgery, and in those where loosening did occur due to osteoporosis, delayed onset of resorption was seen, but resorption and replacement by the patient's own bone were observed 6 months after surgery [18]. In pedicle screw fixation for delayed union of osteoporotic vertebral body fracture in older patients, when granules impregnated with bone marrow blood were implanted into the bony defect of the fractured vertebral body, the defects in the bone cortex in the anterior wall of vertebral body revealed regeneration at 3 months, and the anterior wall fused completely 6 months after surgery [19]. In those cases where blocks were used in the interbody cages during lateral lumbar interbody fusion surgery, the bone fusion rate in the cages was $70.1 \%$. This was equivalent to the results observed when autologous bone blocks are used [20]. During lateral lumbar interbody fusion for intervertebral pseudoarthrosis associated with diffuse idiopathic skeletal hyperostosis, block use within the interbody cages elicited a good bony fusion at 12 months [21]. In the spine, extraosseous bone grafts are frequently used for posterolateral fusion. During posterior occipito-cervical fusion in pediatric patient, when a mixture of autologous iliac cancellous bone and Affinos ${ }^{\circledR}$ granules were implanted between the occipital bone and axis, good bony fusion was observed at 6 months, and remodeling was completed at 12 months [10]. The iliac bone and Affinos ${ }^{\circledR}$ granules were mixed in a one-to-one ratio and transplanted into the pedicle resected during the revision surgery after lumbar long fusion. The pedicle was observed to regenerate by 12 months [10].

\section{Benign bone tumor surgery}

We had reported that when granules were used to fill the lesion after curettage of an enchondroma in the finger bones and intraosseous ganglion, resorption started in 1 month, and the granules were completely replaced with the patient's own bone by 7-10 months [22]. Similarly, after filling the site of a curetted chondroblastoma in the scapula with $20 \mathrm{~g}$ of granules, resorption was clearly seen to start from the margin of the artificial bone at 3 months after surgery, and the complete replacement by the patient's own bone was observed at 2 years [10].

\section{Autologous bone harvesting sites}

Autologous bone is often harvested in orthopedic surgery. In a long-segment anterior cervical spinal fusion case, a columnar blocks were implanted to fill the site after $7.5 \mathrm{~cm}$ of the fibula shaft was harvested [23]. Bone formation occurred from the edge of the fibula at 6 months, and the structure of the cortical bone and medullary cavity, which is originally present in the shaft of a long bone, regenerated in 2 years [10]. We also reported that Affinos ${ }^{\circledR}$ is significantly better 
than $\beta$-TCP of a spherical interconnected porous structure that aids bone regeneration when used to fill harvesting sites of the fibula [24]. When filling the harvest site of the cancellous bone in the distal radius with granules, resorption occurred at 1 month, and the granules were replaced completely with the patient's own bone by 12 months [10].

\section{Animal experiments for the development of Regenos ${ }^{\circledast}$; unidirectional porous HAp}

During initial development, in an experiment where grafting was performed in the distal femur of a rabbit, new bone formation and angiogenesis were observed inside the material at an early stage [5]. In another rabbit experiment where the graft was inserted into the tibial fenestration in contact with both the cortical bone and the medullary cavity, new bone formation and angiogenesis were observed inside the material early after implantation [25]. The new bone was conserved long-term (2 years after implantation) [26]. In the latter model, an osteon-like structure was observed inside the artificial bone at 26 weeks [6]. The vascular-like structure was preserved inside the artificial bone, and the living bone was retained at 104 weeks [27]. Additionally, in an experiment pertaining to long-term implantation into the tibial fenestration of beagle dogs, it was confirmed that the HAp blocks were partially absorbed and replaced with the host bone after 2 years [28].

In another experiment a beagle high tibial osteotomy model was used as a pre-clinical animal model. New bone formation was observed at the interface between the Regenos ${ }^{\circledR}$ block and the host bone at 6 weeks, indicating excellent osteoconductivity, and bony fusion was achieved in 12 weeks [29]. In a goat laminoplasty model, new bone formation was commonly seen at the laminar spacers implanted between the opened lamina; however, deformation of the spacers was observed to occur at a high rate simultaneously [30].

In an experiment where columnar blocks were implanted in the back muscles of beagle dogs, angiogenesis, and invasion of fibrous tissue were seen inside the artificial bones. However, no new bone formation was observed, clearly indicating that the osteoinductive ability was not similar to that of other HAp materials [31].

Other investigators have reported that a scaffold made of HAp with a unidirectional porous structure was more useful than a spherical interconnected porous structure since it could be impregnated with more cells [32]. When recombinant human bone morphogenetic protein- 2 was implanted in bony defects of the skull in mice, significantly more new bone formation was observed than when HAp with a spherical interconnected porous structure was used [33]. Finally, thermal stimulation was found to promote new bone formation in the blocks implanted in rat tibia [34].

\section{Clinical applications of Regenos ${ }^{\circledR}$; unidirectional porous HAp}

We have used Regenos ${ }^{\circledR}$ in various orthopedic surgery. Herein, we reviewed the published cases in each orthopedic field.

\section{Trauma surgery}

In trauma cases, after filling the bony defects with blocks during plate fixation for distal radius fractures, satisfactory new bone formation inside Regenos ${ }^{\circledR}$ block was confirmed by biopsy 12 months later [35]. We had also reported that after filling the bony defects with granules and blocks during internal fixation for calcaneal fractures, bony fusion was achieved at 3 months due to a good osteoconductivity [36].

\section{Osteotomy of the extremities}

We had reported that in high tibial osteotomy for knee osteoarthritis, after we filled the osteotomy site with blocks and granules, adequate bony fusion due to good osteoconductivity and new bone formation were observed at the hinge joints at 6 months. Moreover, some resorption was inclined to occur in blocks at 12 months after implantation [37].

\section{Spine surgery}

Regarding spine surgery, HAp is frequently used as a laminar spacers in cervical laminoplasty. Bone ingrowth has been seen at the interface between the opened lamina and laminar spacers used for double-door laminoplasty, due to their good osteoconductivity. Although deformations (such as cracks, crushing, and wear) and changes in absorption were seen in $21 \%$ of cases, the clinical course was not affected [38]. On the other hand, we had reported that Regenos ${ }^{\circledR}$ is not a suitable spacer for open-door laminoplasty since it has been damaged after surgery in many cases, some of which required reoperation [39].

\section{Benign bone tumor surgery}

In a report from another institution, a good bone formation was observed in 44 cases of benign bone tumors in which Regenos ${ }^{\circledR}$ was used as a bone graft after curettage [40]. Moreover, regeneration was evidenced in the cortical bone and resorption and remodeling were observed in the medullary cavity. 


\section{Autologous bone harvesting sites}

Also in a report from another institution, when columnar blocks were implanted in the harvesting site of fibula in a pediatric patient, complete regeneration of the host bone with a tubular structure was observed 5 years after surgery [41].

\section{Discussion}

We comprehensively reviewed the data obtained from animal experiments and clinical cases regarding artificial bones with a unidirectional porous structure. The greatest feature is that the unidirectional porous structure allows blood to rapidly reach deep inside the material by a capillary effect $[6$, 7]. It is reported that pore throat size and connectivity determine bone and tissue ingrowth into porous implants and narrow pore throats inhibited tissue differentiation in pores [42]. In that point, unidirectional porous structure which is unified size has no narrow pore throats. Therefore, tissue could be easily reach deep inside the material through unidirectional pore as well as blood at the shortest distance even though an artificial bone. These are considered as the mechanism of favorable bone regeneration with unidirectional porous structure or bone formation in the unidirectional pore.

In fact, unidirectional porous $\beta$-TCP, Affinos ${ }^{\circledR}$ promotes angiogenesis than $\beta$-TCP with a spherical interconnected porous structure [12] and absorption and replacement by the patient's own bone occurred earlier in Affinos ${ }^{\circledR}$ than in $\beta$-TCP with a spherical interconnected porous structure [16].

On the other hand, unidirectional porous HAp, Regenos ${ }^{\circledR}$ was also partially absorbed and replaced with the host bone in animal models [27, 28] and clinical cases [37, 40], despite the fact that HAp is basically believed as a non-biodegradable material. Moreover, there is a case report that Regenos ${ }^{\circledR}$ was completely absorbed and regenerated by the host bone in a child [41]. The resorption of interconnected porous HAp implants correlate with the normal bone turnover or activity of osteoclasts in general [43]. The authors speculate that the thin walls of Regenos ${ }^{\circledR}$, by the freeze-casting technique, and the stimulus of blood cells and cytokines from the small vessels may play an important role in the resorption and bone regeneration with bone turnover [28].

In clinical situation, it is difficult to evaluate bone formation or regeneration by histological examination. We reported only one case that satisfactory new bone formation inside the Regenos ${ }^{\circledR}$ was histologically confirmed by biopsy [35]. Therefore, we usually use imaging modality to confirm the new bone formation or replacement with the host bone. Although X-ray is the first choice for these evaluations [44], CT scan is also useful [45]. It is desirable that the evaluation method would be unified in the future.
We are currently conducting research on Affinos ${ }^{\circledR}$, to further expand its original function as a resorbable bone regeneration material. We had previously reported that when teriparatide was administered intermittently after implantation of a block in a rabbit model for tibial fenestration, bone formation inside the artificial bone was significantly promoted when compared to the use of a block implantation alone [46]. Teriparatide is a therapeutic drug for osteoporosis that has a new bone formation effect which is greatly enhanced when used in elderly patients. Experimental results have demonstrated that teriparatide has a good compatibility with Affinos ${ }^{\circledR}$. We are also focusing on the possibilities of platelet-rich plasma (PRP)-impregnated Affinos ${ }^{\circledR}$ by taking advantage of the important ability of artificial bones with a unidirectional porous structure to be rapidly impregnated with blood by a capillary effect. We had reported that both the impregnation amount and rate of PRP with Affinos ${ }^{\circledR}$ were significantly higher than those of $\beta$-TCP with a spherical interconnected porous structure [47]. Further clinical applications of Affinos ${ }^{\circledR}$ with teriparatide as well as PRP are expected.

\section{Conclusion}

The unidirectional porous $\beta$-TCP, Affinos ${ }^{\circledR}$ has an acceptable performance as a resorbable bone regeneration material. A well-balanced resorption and replacement by the host bone occur early after implantation both in animal and human experiments, including clinical applications. Similarly, animal experiments have confirmed that unidirectional porous HAp, Regenos ${ }^{\circledR}$ is associated with a long-standing vascularlike structure within the pores, and living bone formation. Regenos ${ }^{\circledR}$ has shown excellent osteoconductivity early after implantation in clinical cases. Both of these artificial bones with unidirectional porous structure are suitable for most cases in orthopedic surgery.

Supplementary Information The online version contains supplementary material available at https://doi.org/10.1007/s10047-021-01270-8.

Acknowledgments This study was granted and conducted in collaboration with Kuraray Co., Ltd.

Author contributions The idea for the article, Toru Funayama and Masashi Yamazaki; performed the literature search and data analysis, Toru Funayama, Hiroshi Noguchi, Hiroshi Kumagai, Kosuke Sato and Tomokazu Yoshioka; drafted and critically revised the work, Toru Funayama.

\section{Declarations}

Conflicts of interest Toru Funayama and Masashi Yamazaki received a research grant from Kuraray Co., Ltd. 
Open Access This article is licensed under a Creative Commons Attribution 4.0 International License, which permits use, sharing, adaptation, distribution and reproduction in any medium or format, as long as you give appropriate credit to the original author(s) and the source, provide a link to the Creative Commons licence, and indicate if changes were made. The images or other third party material in this article are included in the article's Creative Commons licence, unless indicated otherwise in a credit line to the material. If material is not included in the article's Creative Commons licence and your intended use is not permitted by statutory regulation or exceeds the permitted use, you will need to obtain permission directly from the copyright holder. To view a copy of this licence, visit http://creativecommons.org/licenses/by/4.0/.

\section{References}

1. Campana V, Milano G, Pagano E, Barba M, Cicione C, Salonna G, et al. Bone substitutes in orthopaedic surgery: from basic science to clinical practice. J Mater Sci Mater Med. 2014;25:2445-61.

2. Urabe K, Itoman M, Toyama Y, Yanase Y, Iwamoto Y, Ohgushi $\mathrm{H}$, et al. Current trends in bone grafting and the issue of banked bone allografts based on the fourth nationwide survey of bone grafting status from 2000 to 2004. J Orthop Sci. 2007;12:520-5.

3. Uchiyama K, Inoue G, Takahira N, Takaso M. Revision total hip arthroplasty-salvage procedures using bone allografts in Japan. J Orthop Sci. 2017;22:593-600.

4. Myeroff C, Archdeacon M. Autogenous bone graft: donor sites and techniques. J Bone Joint Surg Am. 2011;93:2227-36.

5. Suetsugu Y, Hotta Y, Iwasashi M, Sakane M. Structural and tissue reaction properties of novel hydroxyapatite ceramics with unidirectional pores. Key Eng Mater. 2007;330-332:1003-6.

6. Makihara T, Sakane M, Noguchi H, Tsukanishi T, Suetsugu Y, Yamazaki M. Formation of osteon-like structures in unidirectional porous hydroxyapatite substitute. J Biomed Mater Res B Appl Biomater. 2018;106:2665-72.

7. Makihara T, Sakane M, Noguchi H, Yamazaki M. The balance between bone formation and material resorption in unidirectional porous $\beta$-tricalcium phosphate implanted in a rabbit tibia. Key Eng Mater. 2016;696:177-82.

8. Sakane M, Tsukanishi T, Funayama T, Kobayashi M, Ochiai $\mathrm{N}$. Unidirectional porous $\beta$-tricalcium phosphate bone substitute: examination of balance between new bone formation and absorption. Key Eng Mater. 2012;493-494:132-4.

9. Kumagai H, Makihara T, Funayama T, Sato K, Noguchi H, Abe $\mathrm{T}$, et al. Angiogenesis and new bone formation in novel unidirectional porous beta-tricalcium phosphate: a histological study. J Artif Organs. 2019;22:294-9.

10. Funayama T, Noguchi H, Kumagai H, Yoshioka T, Yamazaki M. A novel unidirectional porous $\beta$-tricalcium phosphate bone substitute in orthopedic surgery: a technical note and case illustrations. Cureus. 2020;12:e7465.

11. Sato K, Kumagai H, Funayama T, Yoshioka T, Shibao Y, Mataki $\mathrm{K}$, et al. Posterolateral lumbar spine fusion with unidirectional porous beta-tricalcium phosphate in a canine model. J Artif Organs. 2020;23:365-70.

12. Murayama A, Ajiki T, Hayashi Y, Takeshita K. A unidirectional porous beta-tricalcium phosphate promotes angiogenesis in a vascularized pedicle rat model. J Orthop Sci. 2019;24:1118-24.

13. Izawa S, Funayama T, Iwasashi M, Tsukanishi T, Kumagai $H$, Noguchi $\mathrm{H}$ et al. The use of unidirectional porous $\beta$-tricalcium phosphate in surgery for calcaneal fractures: a report of four cases. Foot Ankle Online J 2017. https://doi.org/10.3827/faoj. 2017.1004.0002
14. Kumagai H, Iwasashi M, Funayama T, Nakamura S, Noguchi H, Koda M, et al. Surgical repair of acetabular fracture using unidirectional porous $\beta$-tricalcium phosphate. Case Rep Orthop 2019;6860591.

15. Muramatsu K, Gandionco JA, Suguitan AA, Tani Y, Iwanaga R, Hashimoto $\mathrm{T}$, et al. Unidirectional porous $\beta$-tricalcium phosphate: a new bone filling substitute for treatment of distal radius fracture in the elderly population. J Hand Surg Asian Pac. 2020;25:59-66.

16. Kikuchi N, Yoshioka T, Arai N, Hyodo K, Kanamori A, Yamazaki M. A radiological study of bone remodeling with two different types of porous $\beta$-tricalcium phosphate in humans. Sci Rep. 2020;10:19886.

17. Kikuchi N, Yoshioka T, Taniguchi Y, et al. Use of unidirectional and spherical porous $\beta$-tricalcium phosphate in opening-wedge high tibial osteotomy: a case series. J Rural Med. 2021;16:52-5.

18. Funayama T, Tsukanishi T, Kumagai H, Noguchi H, Izawa S, Abe $\mathrm{T}$, et al. A novel unidirectional porous $\beta$-tricalcium phosphate grafting for vertebral fracture in the elderly: preliminary case series. J Rural Med. 2019;14:211-5.

19. Funayama T, Noguchi H, Mataki K, Yamazaki M. A novel unidirectional porous $\beta$-tricalcium phosphate grafting impregnated with bone marrow blood collected from unfractured vertebral bodies for non-union of osteoporotic vertebral fracture: a preliminary case report. J Orthop Case Rep. 2020;9:50-3.

20. Kumagai H, Abe T, Koda M, Nagashima K, Miura K, Mataki $\mathrm{K}$, et al. Unidirectional porous $\beta$-tricalcium phosphate induces bony fusion in lateral lumbar interbody fusion. J Clin Neurosci. 2019;59:232-5.

21. Funayama T, Fujii K, Abe T, Kumagai H, Nagashima K, Miura $\mathrm{K}$, et al. Spontaneous symptomatic lumbar intervertebral pseudoarthrosis associated with diffuse idiopathic skeletal hyperostosis treated with a combined posteroanterior fusion: a case report and review of literature. J Spine Surg. 2020;6:626-30.

22. Ikumi A, Funayama T, Tsukanishi T, Noguchi H, Yamazaki M. Novel unidirectional porous $\beta$-tricalcium phosphate used as a bone substitute after excision of benign bone tumors of the hand: a case series. J Hand Surg Asian Pac. 2018;23:424-9.

23. Funayama T, Abe T, Noguchi H, Miura K, Mataki K, Takahashi $\mathrm{H}$, et al. Severe, rigid cervical kyphotic deformity associated with SAPHO syndrome successfully treated with three-stage correction surgery combined with $\mathrm{C} 7$ vertebral column resection: a technical case report. Spine Deform. 2021;9:285-92.

24. Noguchi H, Funayama T, Koda M, Iijima Y, Kumagai H, Ishikawa $\mathrm{T}$, et al. A unidirectional porous beta-tricalcium phosphate material (Affinos ${ }^{\circledR}$ ) for reconstruction of bony defects after excision of fibular bone for spinal surgery graft. J Clin Neurosci. 2019;66:71-6.

25. Iwasashi M, Sakane M, Suetsugu Y, Ochiai N. Bone regeneration at cortical bone defect with unidirectional porous hydroxyapatite in vivo. Key Eng Mater. 2009;396-398:11-4.

26. Sakane M, Noguchi H, Funayama T, et al. Novel scaffold for bone tissue engineering: unidirectional porous hydroxyapatite. In: Nusem I, editor., et al., Bone grafts: procedures, complications and alternatives. Hauppauge, NY: Nova Science Publishers; 2013. p. 29-40.

27. Iwasashi M, Funayama T, Watanabe A, Noguchi H, Tsukanishi $\mathrm{T}$, Suetsugu $\mathrm{Y}$, et al. Bone regeneration and remodeling within a unidirectional porous hydroxyapatite bone substitute at a cortical bone defect site: histological analysis at 1 and 2 years after implantation. Materials. 2015;8:4884-94.

28. Noguchi H, Sakane M, Watanabe A, Tsukanishi T, Wadano Y, Yamazaki M. A novel unidirectional porous hydroxyapatite in canines. Bioinspir Biomim Nanomater. 2014;3:228-34.

29. Watanabe A, Sakane M, Funayama T, Iwasashi M. Novel unidirectional porous hydroxyapatite used as a bone substitute for tibial wedge osteotomy in canines. Biomater Res. 2010;14:6-9. 
30. Funayama T, Noguchi H, Tsukanishi T, Sakane M. Histological analysis of bone bonding and ingrowth into connected porous hydroxyapatite spacers in spinal surgery. Key Eng Mater. 2013;529-530:309-12.

31. Noguchi H, Watanabe A, Funayama T, Tsukanishi T, Wadano Y, Sakane M. A novel unidirectional porous hydroxyapatite cylinder implanted in the dorsal muscles of dogs promotes fibrous tissue vascularization and invasion. Key Eng Mater. 2013;529-530:275-8.

32. Tanaka M, Haniu H, Kamanaka T, Takizawa T, Sobajima A, Yoshida K, et al. Physico-chemical, in vitro, and in vivo evaluation of a 3D unidirectional porous hydroxyapatite scaffold for bone regeneration. Mater Basel. 2017;10:33.

33. Kashiwazaki H, Harada N, Akazawa T, Kabir MA, Minamida Y, Murata M. Bone augmentation using novel unidirectional porous hydroxyapatite with bone morphogenetic protein-2 on rat skull. J Hard Tissue Biol. 2013;22:337-42.

34. Ota T, Nishida Y, Ikuta K, Kato R, Kozawa E, Hamada S, et al. Heat-stimuli-enhanced osteogenesis using clinically available biomaterials. PLoS One. 2017;12:e0181404.

35. Iwasashi M, Muramatsu T, Sakane M. Radiological and histological evaluation of Regenos ${ }^{\circledR}$ which implanted in human radial fracture: a clinical case report. Key Eng Mater. 2013;529-530:313-6.

36. Ikumi A, Iwasashi M, Muramatsu T, Li S, Hangai M, Sakane M, et al. Clinical and radiological evaluation of unidirectional porous hydroxyapatite (Regenos $®)$ for intra-articular calcaneal fracture with large bone defect. Foot Ankle Online J. 2014. https://doi.org/ 10.3827/faoj.2014.0702.0005.

37. Uemura K, Kanamori A, Aoto K, Yamazaki M, Sakane M. Novel unidirectional porous hydroxyapatite used as a bone substitute for open wedge high tibial osteotomy. J Mater Sci Mater Med. 2014;25:2541-7.

38. Noguchi H, Koda M, Funayama T, Kumagai H, Abe T, Nagashima $\mathrm{K}$, et al. Bone bonding, displacement, and absorption in cases of double-door laminoplasty with unidirectional porous hydroxyapatite spacers. J Clin Neurosci. 2019;62:46-52.

39. Noguchi H, Koda M, Funayama T, Kumagai H, Saito J, Mannoji C, et al. Regenos spacers are not suitable for open-door laminoplasty because of serious adverse events caused by their insufficient mechanical strength. J Clin Neurosci. 2018;56:50-5.

40. Kunisada T, Hasei J, Fujiwara T, Nakata E, Yokoo S, Demiya $\mathrm{K}$, et al. Radiographic and clinical assessment of unidirectional porous hydroxyapatite to treat benign bone tumors. Sci Rep. 2020;10:21578.

41. Demiya K, Kunisada T, Nakata E, et al. Regeneration of the fibula with unidirectional porous hydroxyapatite. Case Rep Orthop. 2019;2019:9024643.

42. Otsuki B, Takemoto M, Fujibayashi S, et al. Pore throat size and connectivity determine bone and tissue ingrowth into porous implants: three-dimensional micro-CT based structural analyses of porous bioactive titanium implants. Biomaterials. 2006;27:5892-900.

43. Tamai N, Myoui A, Kudawara I, et al. Novel fully interconnected porous hydroxyapatite ceramic in surgical treatment of benign bone tumor. J Orthop Sci. 2010;15:560-8.

44. Damron T, Lisle J, Craig T, et al. Ultraporous $\beta$-tricalcium phosphate alone or combined with bone marrow aspirate for benign cabitary lesions. J Bone Joint Surg Am. 2013;95:158-66.

45. Tanaka T, Kumagae Y, Chazono M, et al. A novel evaluation system to monitor bone formation and $\beta$-tricalcium phosphate resorption in opening wedge high tibial osteotomy. Knee Surg Sports Traumatol Arthrosc. 2015;23:2007-11.

46. Kumagai H, Funayama T, Sugaya H, Yoshioka T, Makihara T, Tomaru Y, et al. Effects of teriparatide on bone formation in novel unidirectional porous beta-tricalcium phosphate. J Biomater Appl. 2019;34:721-7.

47. Arai N, Yoshioka T, Sugaya H, Kanamori A, Yamazaki M, et al. How much platelet-rich plasma can be soak-loaded onto betatricalcium phosphate? A comparison with or without a unidirectional porous structure. J Rural Med. 2021;16:14-21.

Publisher's Note Springer Nature remains neutral with regard to jurisdictional claims in published maps and institutional affiliations. 